\title{
De mujeres, pícaros $y$ fugas: memorias de la guerra de Malvinas
}

Veronica Perera

Doctora en Sociología (New School for Social Research, Nueva York, EEUU); Docente Investigadora en la Universidad Nacional de Avellaneda, Departamento de Humanidades y Artes, Argentina; Investigadora asociada al Núcleo de Estudios de la Memoria Social, IDES, CISCONICET, Argentina.

Areas actuales de investigación: arte y politica; teatro independiente y movimiento de derechos humanos en Argentina; estudios de la memoria colectiva sobre la violencia política en Argentina.

Recebido em: 30 de setembro de 2016 Contacto: maria.perera@purchase. Aceito em: 30 de outubro de 2016 edu 
Palabras clave: Argentina;

Guerra de Malvinas 1982;

Teatro independiente.

Keywords: Argentina; Malvinas

War 1982; Independent

Theater.
Si al decir de Lorenz (2013) las políticas de Memoria, Verdad y Justicia de los años 2003-2015 delinearon un marco memorial con nuevas posibilidades para revisar "Malvinas", ¿cómo aparece este escenario político de "malvinización" en el escenario teatral independiente de Buenos Aires? ¿Cómo se capta y se traduce; se espeja y se subvierte; se narran y se elaboran las memorias de Malvinas y sus dilemas en los textos dramáticos producidos alrededor del 30 aniversario de la guerra? A partir del análisis de Piedras dentro de la Piedra de Mariana Mazover, presentada el 30 de marzo de 2012 en el Teatro La Carpintería de Buenos Aires, el artículo analiza el modo en que esta dramaturgia recupera la intervención de las mujeres en la suerra de 1982; y elabora sobre la libertad que el teatro comparte con la ficción literaria para socavar nociones fundamentales que sostienen la guerra: identidad nacional, patria, honor.

According to Lorenz (2013), the Memory, Truth and Justice policies implemented in Argentina between 2003 and 2015 offered new possibilities to revise "Malvinas" and question its meanings. How does this political scenario of "Malvinización" appear on independent theaters' stages in Buenos Aires? How do dramatic texts translate, reflect, subvert, narrate and elaborate the memories of the Malvinas War and its dilemmas? This paper analyzes Mariana Mazover's Piedras dentro de la Piedra, presented on March 30th, 2012, three days before the 30th anniversary of the beginning of the war, in La Carpintería Theater in Buenos Aires. We examine how this play recovers the intervention of women in the war, and in which way it explores the possibility theater shares with literary fiction of undermining key notions that symbolically support the war: national identity, motherland, and honor. 
DE MUJERES, PÍCAROS Y FUGAS: MEMORIAS DE LA GUERRA DE MaLVINAS

“El acto del monumento no es la memoria, sino la fabulación”-Gilles Deleuze, ¿Qué es la filosofía?

Entre 2003 y 2015, la construcción de memorias del terrorismo de Estado, la visibilización de crímenes de lesa humanidad, y la justicia transicional fueron, además de centrales para la agenda del gobierno nacional en Argentina, criterios orientadores de políticas culturales. Estas políticas abrieron un espacio de encuentro entre el movimiento de derechos humanos y el teatro independiente que se expresó en distintas partes de la Argentina, y especialmente en la ciudad de Buenos Aires. Además del conocido Teatro x la Identidad, uno de los "brazos artísticos" de las Abuelas de Plaza de Mayo, surgieron colectivos y eventos teatrales potentes a la hora de resignificar sentidos del pasado reciente, resituar violencias y actualizar luchas por los derechos humanos. Este espacio vinculó teatristas de distintos oficios con agencias estatales, asociaciones profesionales de artistas, organismos de derechos humanos y concursos de dramaturgia que invitaban a narrar tanto el pasado reciente como las aspiraciones democráticas y la expansión de derechos del presente. Estos circuitos rizomáticos y heterogéneos, entrelazados pero diferenciados de los partidos políticos y de la militancia organizada, visibilizaron denuncias por fuera de la justicia institucional. Antes que mostrar evidencias, hicieron preguntas; más que ideología, movilizaron afectos; más que cursos de acción a seguir, abrieron reflexiones múltiples. Si bien fue un hacer estético-político nacido al calor de las políticas públicas de Memoria, Verdad y Justicia de los años 2003-2015, se trató, fundamentalmente de micropolítica. 
"Malvinas fue uno de los temas dominantes del concurso", me dijo el dramaturgo Roberto Perinelli refiriéndose al certamen "sobre la vida en democracia" organizado por la entonces Secretaría de Cultura de la Nación y el Teatro del Picadero en Buenos Aires para homenajear a Teatro Abierto $1981^{1}$. Es que el trigésimo aniversario de la guerra de Malvinas apareció como huella del pasado-usando palabras de Maurice Halbwachs-recuperada no solo por la gestión diplomática (la Presidenta Fernández habló, por ejemplo, en el Comité de Descolonización de las Naciones Unidas) y por organizaciones militantes de ex combatientes, sino también por la imaginación de una generación joven de dramaturgo/as. Treinta años después, el teatro independiente se hizo eco del teatro de operaciones militares de 1982. Se adaptaron ficciones fundantes sobre aquella guerra: Mariana Mazover escribió Piedras dentro de la Piedra (2014) a partir de la novela picaresca de Rodolfo Fogwill, Los Pichiciegos (1983)-y de ella me ocuparé aquí. Lo mismo hizo Diego Quiroz con "Los Tururú”. Carlos Gamberro adaptó su propia ficción Las Islas (1996), y la puso en escena con el mismo nombre bajo la dirección de Alejandro Tantanian. A propósito del aniversario, Mariano Saba ganó con "Lógica del Naufragio" el concurso realizado por el Instituto Nacional del Teatro.

Si al decir de Federico Lorenz (2013) las políticas públicas de Memoria, Verdad y Justicia de los años 2003-2015 delinearon un marco memorial con nuevas posibilidades para revisar "Malvinas"; si recrearon un territorio donde volver a disputar sentidos de la guerra de 1982, ¿cómo aparece este

1. Entrevista personal, 3 de marzo, 2016. 
De mujeres, pícaros y fugas: Memorias de la guerra de Malvinas

escenario político de "Malvinización" en el escenario teatral independiente de Buenos Aires? ¿Cómo se capta y se traduce; se espeja y se subvierte; se narra y se elabora el marco memorial de Malvinas y sus dilemas, en algunas producciones teatrales? Para elaborar estas preguntas, aquí me concentro en Piedras dentro de la Piedra (2014), escrita por Mariana Mazover a partir de la novela picaresca de Rodolfo Fogwill, Los Pichiciegos (1983); estrenada el 30 de marzo de 2012, en el Teatro de La Carpintería en Buenos Aires, y publicada en el 2014 por la editorial Libretto de Buenos Aires. Las funciones, que recibieron aproximadamente dos mil espectadores, se extendieron hasta noviembre del mismo ańo. En varias oportunidades, se realizaron charlas con personalidades como la investigadora y crítica teatral Beatriz Trastoy, la dramaturga Susana Torres Molina, o el poeta y conscripto sobreviviente de la guerra, Hugo Emilio Sánchez. Se hicieron, además, funciones en escuelas secundarias. Mi análisis del texto dramático de Mazover incluye la comparación con dos obras ganadoras del concurso homenaje a Teatro Abierto en 2015, también de dramaturgas: "Mares de Piedra" de Roxana Aramburú y "Grietas" de Lola Banfi fueron presentadas en octubre y noviembre de 2015, en el "Teatro del Picadero", también en Buenos Aires.

Dramaturgos argentinos como Roberto Cossa, Roberto Perinelli o Mauricio Kartún, contemporáneos de la guerra y pertenecientes a la generación de Teatro Abierto-aquel ciclo que reunió a teatristas destacados y entonces silenciados con veinticinco mil espectadores para convertirse, luego del atentado militar al Teatro del Picadero que los alojaba, en icono de resistencia cultural contra la última dictadura-me hablaron de algo así como un "sentir generacional”. Kartún, por ejemplo, reconoció que todavía hoy le 
resulta muy difícil "limpiar el pensamiento sobre Malvinas". "Está siempre imbricada la especulación política y estratégica del gobierno militar de utilizar la guerra como mecanismo de continuidad" me dijo, "y de ganar presencia pública y eternizarse. Es difícil dar opinión sobre Malvinas porque hay que dividir muchas cosas. Malvinas fue aquello que no pudimos resolver, y que no teníamos la voluntad de resolver." ${ }^{2}$

Treinta ańos después de la guerra, una nueva generación parece poder "dividir las cosas" y se acerca al conflicto bélico de 1982 para producir textos dramáticos. Las políticas públicas de Memoria, Verdad y Justicia generaron un marco memorial que, entre otras cosas, al "re-malvinizar" la conversación pública (y más abajo me detengo en eso), repartió nuevas posibilidades a teatristas independientes para asomarse y revisitar la guerra contra Gran Bretaña que inició el final de la última dictadura cívico-militar en Argentina. "Yo no había nacido", me dijo la autora de "Grietas", una de las ganadoras del concurso homenaje a Teatro Abierto que mencioné arriba; "pero me dieron ganas de meterme en el tema porque me parecía que era algo de lo que no se podía hablar"3. Mazover estrenó Piedras dentro de la Piedra el 30 de marzo de 2012, dos días antes del trigésimo aniversario del inicio de la guerra. Entendió su obra como "una superficie de comunicación” que "se enlazaba" a la constitución de un problema que se volvía culturalmente legible. Después de mucha postergación, y a través de políticas reparatorias, sostiene Mazover, el ex combatiente de Malvinas apareció como sujeto de

2. Entrevista personal, 28 de agosto de 2014 .

3. Entrevista personal, 8 de marzo de 2016. 
DE MUJERES, PÍCAROS Y FUGAS: MEMORIAS DE LA GUERRA DE MaLVINAS

derecho, merecedor de compensación material y reconocimiento simbólico por parte del Estado ${ }^{4}$.

\section{MALVINIZACIÓN RECIENTE, DISPUTAS DE SENTIDO}

El marco memorial desde la pos-dictadura en 1983 hasta el inicio de la gestión de Menem en 1989 aparecía tensionado por aquello que Federico Lorenz $(2006,2013)$ identificó como la “desmalvinización” de la política y la "malvinización" defendida casi exclusivamente por las asociaciones políticas de los ex combatientes. La "desmalvinización” comenzó en junio de 1982 con la derrota misma, y desde las propias Fuerzas Armadas, cuando ocultaron a los soldados sobrevivientes, prohibieron sus testimonios y persiguieron a sus asociaciones políticas. La desmalvinización portaba, en la posdictadura temprana, una aspiración democrática fundamental: "Para los militares," escribía el politólogo Alain Rouquié en 1983, "las Malvinas serán siempre la oportunidad de [...] rehabilitarse. Intentarán hacer olvidar la 'guerra sucia' contra la subversión y harán saber que ellos tuvieron una función evidente y manifiesta que es la defensa de la soberanía nacional" (Humor 101 en Lorenz, 2007, 37). Fueron varias las alertas en esta línea: el filósofo León Rotzichtner, por ejemplo, argumentaba sobre la "guerra limpia" y los "muertos legítimos" que la dictadura militar podía confesar como fundamento para reconstruir la nación. El periodista Horacio Verbitsky denunciaba los peligros de abstraer el inicio de la contienda de su contexto histórico, y de los años anteriores como maniobra para sacralizar la

4. Entrevista personal, 24 de junio, 2016. 
guerra y resacralizar a las Fuerzas Armadas. Va de suyo que para el gobierno de Alfonsín el impulso democrático encarnado en la desmalvinización se volvió aún más urgente con las sublevaciones militares de 1987 y 1988, amenazantes de la incipiente estabilidad de las instituciones democráticas. La desmalvinización implicó, entonces, "la homologación entre cualquier reivindicación de la justicia de las causas para la guerra y de quienes participaron en ella con la dictadura militar" (Lorenz, 2007, 36).

Durante la gestión de Menem (1989-1999), desde la perspectiva de la "pacificación y reconciliación nacional”, se creó la Federación de Veteranos de Guerra, alineada con el gobierno nacional y vinculada con líderes carapintadas de las sublevaciones militares de 1987 y 1988. Las respuestas a algunos reclamos del sector vinieron de la mano de la cooptación del movimiento de ex combatientes por el Estado, y de la reinserción de la guerra de Malvinas en un relato épico patriótico. Se trata, en última instancia, de un relato que inscribe a "Malvinas" en una historia nacional inaugurada en el siglo XIX. Se trata de una teleología de patria y guerra, fundadora de la argentinidad (Kohan, 2014b); donde a pesar de algunas derrotas como la de 1982, asume que el destino es siempre la victoria y la realización como pueblo en una plenitud territorial (Lorenz, 2013).

Las políticas de Memoria, Verdad y Justicia del período 2003-2015 reconfiguraron la guerra de Malvinas como territorio disputado por nuevas construcciones de sentido. Un territorio conformado por una renovada conversación pública desplegada, con un lenguaje diplomático, en instituciones internacionales (de las Naciones Unidas y de la Comisión Interamericana de Derechos Humanos); con un lenguaje jurídico, en la justicia penal y los 


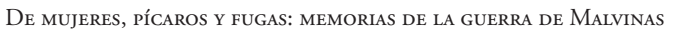

Veronica Perera

juicios de lesa humanidad; y con vocabularios estético-políticos, en políticas y prácticas culturales. Si bien reapareció el relato de la guerra como gesta y como causa nacionalista (Lorenz, 2013), organizado alrededor de héroes y caídos en combate; el reclamo de soberanía sobre las Islas emergió, en estos años, entretejido a nuevas tramas discursivas y enlazado a matices diferentes. El discurso gubernamental volvió a reinterpretar "Malvinas" en clave anti-imperialista, denunciando a las Islas como anacrónico bastión colonial aún existente en el siglo XXI. Reinstaló "Malvinas" dentro del proyecto de construcción política latinoamericana: a través de CELAC y UNASUR buscó apoyo regional a la vía diplomática y dialogal como estrategia para la recuperación de las Islas. Y desplazó la defensa de la soberanía sobre el territorio del Atlántico Sur a la defensa de la soberanía económica y la restructuración de la deuda externa 5 . Por otro lado, el Museo de Malvinas, emplazado en el predio del ex Centro Clandestino de Detención, Tortura y Exterminio más grande de la última dictadura, la ex Escuela Superior de Mecánica de la Armada, devenido en "Espacio de Memoria” desde 2004, espacializó el esfuerzo por resignificar las prácticas de los cuadros militares para con los soldados durante la guerra y catalogarlas como tortura, parte de los crímenes de lesa humanidad que desde 2006 se juzgan dentro de la Justi-

5. El 10 de junio de 2015 se inauguró un "Faro de la Soberanía” al lado del Museo de Malvinas. Se buscaba visibilizar, explicaba la Presidenta en el discurso inaugural del Faro de la Soberanía, entre otras, un reclamo permanente por la soberanía argentina sobre las Islas. Pero el discurso pronunciado apuntó a reconfirmar (¿aprovechando la evidente connotación fálica del monumento?) el rechazo gubernamental a la reciente decisión del estadounidense Juez Griesa sobre el pago obligatorio de la Argentina a los usurarios "fondos buitre". Ver https://www.youtube.com/ watch?v=fYDGpR-2RAU 
cia Penal en Argentina. Este esfuerzo, que acomodó demandas de larga data de algunas asociaciones de ex combatientes, estuvo, sin embargo, saturado de ambivalencias y dilemas: "víctimas caídas en combate" y "héroes militares" aparecieron como represores y torturadores de la maquinaria genocida ${ }^{6}$.

Además, la memorialización de la guerra de los últimos años volvió visible y audible la intervención de mujeres en la contienda. Si bien no combatieron como soldadas en las propias zonas del conflicto, realizaron tareas como enfermeras, instrumentadoras quirúrgicas, trabajadoras de terapia intensiva y radio operadoras desde el continente o a bordo del buque hospital Irizar, a metros de Puerto Argentino. El primer reconocimiento oficial les llegó a propósito del trigésimo aniversario durante la gestión del Ministro de Defensa, Arturo Puriccelli (Carbajal 2015). En 2012 fueron invitadas, por primera vez, a participar en un desfile militar junto a ex combatientes. En el 2014 fueron reconocidas por la Ministra de Gobierno de Buenos Aires en el Consejo Provincial de las Mujeres' ${ }^{7}$ y sus experiencias fueron documentadas, también por primera vez, en el libro Mujeres Invisibles de Alicia Panero, junto a las de otras mujeres isleńas y británicas. Para la autora, profesora de

6. Algunos ejemplos elaborados por Lorenz (2013: 196-208): el Presidente Kirchner, con espíritu de homenajear a los héroes de Malvinas, habilitó pensiones honoríficas de guerra para conocidos represores. Estas fueron posteriormente retiradas por el mismo gobierno luego de las denuncias de agrupaciones de ex combatientes. La publicidad de los archivos de la represión permitió establecer en 2010 que el presidente por treinta años de la Comisión de Familiares de Caídos en Malvinas había sido agente de Inteligencia del Batallón 601 entre 1981 y 1983. El primer caído en combate, el oficial Giachino, fue reconocido por sobrevivientes de la Escuela Superior de Mecánica de la Armada (ESMA) como integrante de grupos de tareas y está involucrado en cuatro causas por violaciones a los derechos humanos.

7. http://www.consejomujeres.gba.gob.ar/?p=1274, 1 de abril, 2014. 
DE MUJERES, PÍCAROS Y FUGAS: MEMORIAS DE LA GUERRA DE MALVINAS

Historia y trabajadora en una base militar, se trató de volver audibles silencios inexplicables y abandonos institucionales de casi treinta ańos (Panero, 2014). El Museo Malvinas aloja el testimonio audiovisual de Norma Navarro, enfermera a bordo del Irizar, junto a testimonios de ex combatientes y familiares de caídos. En 2015, la senadora riojana Aguirre de Soria presentó un proyecto de ley para otorgarle una pensión vitalicia "al personal femenino... que en condiciones de verdadero riesgo para su integridad física, mental y espiritual e imbuido de un heroico patriotismo, cumpliera tareas de contención humana y atención sanitaria a los combatientes heridos" (Parrilla 2015, resaltado propio). Es decir, las imágenes y las voces de las mujeres de la guerra que emergieron en los últimos años y especialmente alrededor del trigésimo aniversario, se acomodaron en un registro testimonial y un relato todavía cargado de víctimas y heroínas.

Retomo, entonces, las preguntas que planteé en la introducción: ¿Cómo se capta y se traduce; se espeja y se subvierte, este escenario político de malvinización de los últimos años en Argentina, en el escenario teatral independiente? ¿Cómo afectan las disputas y los nuevos sentidos a los textos dramáticos producidos a propósito del trigésimo aniversario? ¿Qué figuras aparecen? ¿Cómo se visibilizan? Para abordar estas preguntas, me concentro en Piedras dentro de la Piedra (2014), escrita por Mariana Mazover a partir de Los Pichiciegos (1983), la picaresca de Rodolfo Fogwill. La comparo y la contrasto con "Mares de Piedra" de Roxana Aramburú y "Grietas" de Lola Banfi, presentadas en octubre y noviembre de 2015 en el Teatro del Picadero en Buenos Aires. 


\section{MÁS ALLÁ DE VÍCTIMAS: DRAMATURGAS, PÍCARAS, ECÓNOMAS}

Martín Kohan (2014a) entiende que Los Pichiciegos forma parte de la literatura sobre Malvinas regida por el principio de "desarticulación nacional”nada de la gesta nacional, ni la de la victoria ni la de la derrota, queda en pie. La no denuncia sobre la guerra, y la posibilidad de socavar esas nociones que sostienen, simbólicamente, la guerra -patria, nación, honor, sacrificio, etc.-solo le cabe a la ficción literaria. El género testimonial no puede permitirse confrontar lo nacional; no puede dejar de denunciar las distintas atrocidades cometidas a propósito de la guerra: desde la manipulación de la dictadura cívico-militar para permanecer en el gobierno hasta los crímenes de lesa humanidad cometidos. "Y así la guerra" escribe Kohan:

contada [en Los Pichiciegos] sin ese sistema de valores trascendentes, despojada de su lógica primordial, no puede sino desviarse hasta llegar a ser básicamente un juego de astucias, una red comercial de intercambio, un afán sostenido de supervivencia a cualquier precio; sin rastro alguno de épica, de heroísmo, de sacrificio, de valor. (Kohan, 2014a,1).

La dramaturgia de Mazover comparte esa libertad que Kohan le atribuye a la ficción literaria. Igual que Los Pichiciegos, Piedras dentro de la Piedra dramatiza a un grupo de desertores: la cueva y el sótano de máxima seguridad no alojan ni víctimas ni heroes.

Allí se refugian cinco soldados-dos sargentos, dos cabos, un conscripto sin instrucción-y un civil, para sustraerse de la guerra y de toda identificación nacional. Al tiempo que interrumpen el credo nacionalista y toda 


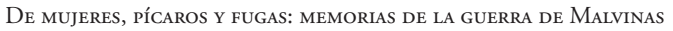

noción de honor, autogestionan un espacio donde protegerse de las peores amenazas y hacer posible la vida en común. Son cuerpos que se acompañan, se desean, se pelean. Se dan calor, acopian e intercambian alimentos y otras mercancías que consiguen de los ingleses, tejen vínculos erótico-afectivos. Construyen infraestructura ("la tobogana de durmientes y placas de metal"), y hasta inventan tecnología (también feminizada) con la expectativa de "patentarla al regreso". La "veleta retrovisora multicardinal”, un artefacto espejado de dudosa utilidad, construido por los integrantes de la cueva, junto a fusiles y pistolas sulfatadas, no hacen más que resaltar un "Estado que renunció al contrato social que lo une al soldado-ciudadano": un Ejército donde los oficiales son enemigos y torturadores de sus propios soldados, quienes están muy mal provistos de armamentos, mal entrenados para combatir, mal alimentados y mal abrigados para soportar las inclemencias del clima de las Islas (Rodríguez, 2016, 4-5).

Pero la obra de Mazover, a diferencia de la picaresca de Fogwill, no se organiza alrededor de un colectivo homosocial y homoerótico de soldados. La presencia de mujeres (y de un civil) en la guerra son una clave en esta trama:

Fui la primera dramaturga y directora que hizo obra sobre Malvinas-me dijo Mazover". Y continuó “[...] hace poco empezaron los reclamos y las mujeres empezaron a contar los vejámenes, las violaciones [...] Sabemos que hubo [seis] enfermeras, que eran parte del ejército pero que no estaban ahí combatiendo. Yo tomé la decisión y dije, las pongo mujeres, soldadas. Y un

8. Entrevista personal, 24 de junio, 2016. 
civil. Para pensar el lugar de la sociedad civil. Ahí aparece el personaje de un camionero que se fue a prestar sus camiones a la guerra.

Piedras... se hace eco, entonces, de un contexto memorial que volvió visible y audible la intervención de mujeres. Pero las imágenes y las voces de las mujeres de la guerra en esta pieza teatral se distancian del registro documental que marcó otras producciones estéticas de esos años-como los testimonios de Mujeres Invisibles de Panero u otras obras teatrales como "Mares de Piedra" de Aramburú; "Grietas" de Banfi o "Islas de la Memoria" de Cardoso. Piedras... se distancia así de la retórica de la gesta, del honor nacional, del sacrificio y de los protagonismos de víctimas y de heroínas. Contrariamente, con una estética realista crítica-reflexiva, la obra teatral de Aramburú, por ejemplo, muestra la participación de instrumentadoras en la contienda: trabajadoras jóvenes dentro de una rama feminizada y desjerarquizada de la profesión médica. Más allá de elaborar sobre la bien estudiada movilización discursiva patriarcal y heteronormativa por parte del régimen militar-en los argumentos, por ejemplo, del "familismo" de Jelin (2010) o los masculinizados padres de la patria de Taylor (1997)-el texto dramático de Aramburú elabora sobre la explotación laboral y el abuso sexual, formas de dominación patriarcal en y para la guerra. Sandra, la protagonista, decide ir a Malvinas como instrumentadora para unirse a su novio conscripto. Una vez allí, es abusada laboral y sexualmente por un mayor quien finalmente concede su baja. "Mares..." denuncia los atropellos y las violaciones propias de Malvinas y de cualquier guerra; y también investiga la menos estudiada división del trabajo organizada en base a una suposición biologizante ("los 
DE MUJERES, PÍCAROS Y FUGAS: MEMORIAS DE LA GUERRA DE MALVINAS

dedos ágiles"), que usa y abusa, para la guerra, rasgos culturalmente codificados como "femeninos".

La obra de Aramburú también expone claves de un relato nacionalista y belicista: "Recuerde:" le ordena el mayor a Sandra, "el enemigo combate para defender el colonialismo; usted tiene detrás la voluntad de toda la $\mathrm{Na-}$ ción Argentina, y la causa de la soberanía y el honor nacional." Pero al poner estas expresiones en boca del mayor (un médico militar violador y probablemente torturador), la obra denuncia el relato nacionalista y triunfalista de la guerra y evoca la figura del héroe. Lo pone en escena, lo visibiliza, pero no lo desarma ni lo subvierte.

"Grietas" de Lola Banfi, desde la misma estética y también ajena a una poética del interrogante, propia del teatro político y del activismo teatral contemporáneo en Buenos Aires (Perera 2015), busca extender el padecimiento de la guerra para incluir el dolor de quienes permanecieron en sus lugares de residencia. Un hermano mellizo y una madre que desde el fuera de escena se hace presente a partir de su debilidad física y su sufrimiento emocional, organizan la obra de la joven dramaturga. Es decir, además de los conflictos y del sufrimiento del que vuelve de la guerra, el texto dramático de Banfi, explora las dificultades y el dolor de quienes reciben a los ex-combatientes. Quien fue a la guerra no sabe cómo volver. Quien se quedó no sabe cómo alojar a quien regresa.

Es decir, tanto "Mares de Piedra" como "Grietas" pluralizan la figura de la víctima más allá de los ex combatientes. Visibilizan la participación de las mujeres y las tramas vinculares malheridas por la guerra. Pluralizan, dispersan. Pero no desarticulan ni descentran la figura de la víctima como organi- 
zadora fundamental de las memorias de Malvinas. Ya no son "Los chicos" de Daniel Kon en 1984. En 2012, son “Las Mujeres de la guerra”. Pero fundamentalmente mujeres víctimas. Mujeres que recuerdan la condición de víctimas abusadas por un Estado que abandonó todas sus responsabilidades del contrato social que lo vincula con, y le impone proteger, al soldado-ciudadano.

Las mujeres de la obra de Mariana Mazover tampoco son vidas que el Estado protege. Son cuerpos tan subalimentados, mal entrenados y mal equipados para la contienda militar como los de sus compañeros varones. Sin embargo, la trama de la obra no les asigna lugares culturalmente codificados como "femeninos", o roles despreciados, degradados, humillados. No se identifican con vínculos traumatizados ni se paralizan por la ausencia y el dolor. No son, fundamentalmente, objetos sexuales a ser abusados por superiores militares; ni enfermeras o instrumentadoras a ser explotadas por la maquinaria bélica de la dictadura cívico-militar (como en la obra de Aramburú); ni madres sufrientes de hijos combatientes (como en la obra de Banfi). Son, al igual que sus compañeros varones, pícaras que se sustraen de la guerra; soldadas-una sargenta y una conscripta-que se evaden de aquello que no eligieron pero se les impuso. Son mujeres empoderadas que construyen y gozan la vida común más allá de las fronteras nacionales. Son líderes capaces de imponer su voluntad entre los pícaros. Al igual que en Los Pichiciegos, la comunidad de desertores de Piedras... está organizada con sentido de mando y liderazgo jerárquico. Pero si bien firme y en principio vertical, el liderazgo de la sargenta Mabel es también amoroso. Un liderazgo vital que se distancia de toda esencia: ni la causa, ni la nación, ni la guerra 


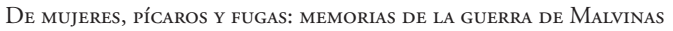

motivan la conducción de esta sargenta. En un mismo parlamento, Mabel alienta con convicción y ternura, en medio de la desesperanza grupal y el horror del afuera, la sobrevivencia de todos a la guerra, el cuidado de los cuerpos y la solidaridad con Olga Ana, quien llegó última y herida a la cueva:

Gandini va a volver. Oscar va a volver. Enrique va a volver. Vos vas a volver. Y los secretos que sabemos acá los vamos a dejar enterrados debajo de las piedras y, cuando estemos en el continente, nadie los va a mencionar. Y el que necesite polvo químico, usa polvo químico. Y si se acaba el polvo químico, sale uno de campana y ayuda al compañero a mover el vientre con dignidad. ¿Te gustan los ñoquis, Olga? (Mazover, 2014, 22-23)

Con su liderazgo de ecónoma, Mabel protege. Conserva el oikos: ese espacio doméstico, material y emocional, que los desertores han construido para abstraerse, en común, de la guerra. Prepara ñoquis de harina y agua; cuestiona los términos de intercambio de mercancías impuestos por otros soldados (“un cigarrillo no vale un jabón”); acompaña la agonía del soldado cordobés; cura la herida de Olga. Mabel afirma, decide, ejecuta: enfrentando la ansiedad de la escasez de alimentos, hace un inventario y raciona las provisiones existentes; luego de muerto el soldado cordobés, reúne el coraje para sacar el cadáver (en trozos, por la falta de espacio) fuera del refugio. Comparte el liderazgo comunitario (con el conscripto Enrique, al comienzo de la obra) y frente a la amenaza final de la llegada del enemigo, con sentido de mando y de responsabilidad colectiva, se entrega primero, junto a Gandini, para no dejarlo solo y para salvar a los restantes integrantes de la cueva ("Voy a 
honrar mi rango, Gandini. Soy Sargento, y este es mi pelotón. [...] Tu hijo, Gandini", Mazover, 2014, 37). Pero antes que un sacrificio en nombre de la nación, el gesto último de Mabel es un acto de solidaridad entre pares, desacoplado del honor, desvinculado de toda gesta. Antes que heroína de Malvinas, Mabel es ecónoma, amiga, líder solidaria.

\section{MÁS ACÁ DEL HONOR Y LA PATRIA: LA SUSTRACCIÓN, LA FUGA, LO NO HUMANO}

"Me interesaba el que se sustrae" me dijo Mazover, "[...] el que no está dispuesto a entrar [...] el que no es enlazado al falso discurso del honor, a toda la retórica de la guerra que sostiene imaginariamente a todos combatiendo". Desde acá, Mazover parodia artificios clave para la construcción de lo nacional. El texto dramático comienza con la pregunta "¿Alta en el cielo?”. A la que Mabel responde: "Dejame entrar, pelotudo." (Mazover, 2014 , 9). Es decir, las palabras con las que comienza el "Saludo a la Bandera” funcionan, en la puesta de Mazover, como la contraseńa que abre la puerta del refugio desertor. Para ser admitidos en la cueva, los ingresantes deben responder "La constelación de la Osa Mayor". Y cuando se vuelve necesario cambiar la contraseńa por motivos de seguridad (el enemigo la pudo haber descubierto si tomó prisionero a Marcelino), esta se convierte en "Los cambiones de Marcelino Jesús" (Mazover, 2014,15). Es decir, un símbolo de construcción nacional (la canción del Saludo a la Bandera) y una performance cotidiana de argentinidad (millones de niños y niñas la cantan todos los días antes de entrar a la escuela) son subvertidos en Piedras..., para operar como llaves que abren la posibilidad material de desertar la guerra, como canales de fuga de la patria. 
De mujeres, pícaros y fugas: Memorias de la guerra de Malvinas

El personaje de Marcelino también parodia la patria. Nieto de un empresario frigorífico rico y propietario de camiones, se suma a la guerra como voluntario por fuera de la institución militar para, aparentemente, ofrecer un servicio como civil. Marcelino presta sus camiones para transportar soldados y lo hace con dedicación y cuidado:

“...[Marcelino] Frena. Se baja y mira en las jaulas que no se haya caído ningún soldado. $\mathrm{O}$ si tienen sed, eso también lo pregunta. Y da de tomar agua del motor", describe Olga Ana (Mazover, 2014, 29). Ese "servicio" de Marcelino, entonces, evidencia y cuestiona el apoyo y la complicidad de la sociedad civil en la guerra. Así como en los últimos años la disputa por la memoria de la última dictadura incluyó el esfuerzo de organizaciones de derechos humanos por revisar la complicidad civil empresaria (en el caso paradigmático, por ejemplo, del empresario Blaquier y la represión en el Ingenio Azucarero Ledesma en Tucumán), la ficción de Mazover interroga, a partir del personaje de Marcelino, la intervención civil en la guerra. Además, detrás de una aparente lealtad y amor a la patria, avanzada la obra, conocemos que Marcelino se sumó a la guerra para "trascender a la vuelta con lo de los camiones civiles que participaron de una guerra" (Mazover, 2014, 24). Es decir, entre la astucia comercial y la aventura deportiva, entre una estrategia de publicidad y el deseo de reconocimiento, Marcelino busca intervenir en Malvinas para conseguir capital simbólico y exhibir sus camiones en el Museo de la Batalla de Yapeyú. El texto dramático de Mazover explora, a partir del personaje de Marcelino, la participación civil en la guerra, más allá del apoyo ideológico o discursivo. Explora, entonces, los negocios de la guerra-o la guerra como negocio. 
Marcelino espeja, además, una zona de encuentro con lo no-humano, ya presente en la novela de Fogwill. Las ovejas son, tanto para algunos pichis en Los Pichiciegos como para Marcelino, objetos de deseo y compañeras sexuales como fuentes proveedoras de alimento y abrigo ("Soñó que se culeaba a una oveja"; "Este me garcha, me pela la lana o me degüella para comer" (Fogwill 2012, [1983], 42, 115-116). Las ovejas son también marcadoras del peligro letal en los campos minados ("Sucede que debajo de la oveja había una mina y al rozarla ella se hizo como si el sol saliera, una luz fuertísima" (Fogwill, 2012 [1983], 116). Lo mismo sucede en Piedras.... A Marcelino le atraen las ovejas, coquetea con ellas y se distrae al punto de poner en riesgo su seguridad y la de todos los integrantes de la cueva. Y cuando las ovejas estallan porque han pisado una mina personal (“¡Cayó primero la pobrecita PUM!", Mazover, 2014:13), los desertores pierden todos los alimentos que habían conseguido de los ingleses. Es decir, el personaje de Marcelino no solamente desnuda y cuestiona la colaboración civil empresaria con la guerra (o la guerra como negocio), sino que desbarata, parodiando, desorganizando, la noción de patria. La patria no es, para Marcelino, un espacio reglado y estable de pertenencia, al cual se le debe lealtad y la obligación de honrar. La patria, o lo que se hace en nombre de, a propósito de, a través de un "servicio a la patria", para Marcelino, expande los límites y las posibilidades de la experiencia-más allá de lo humano.

\section{LA LIBERTAD DE LA PICARESCA (Y DEL TEATRO)}

La obra de Mazover es hija de su tiempo, de un contexto memorial que entre 2003 y 2015 en Argentina, y de la mano de las políticas de Memoria, 
DE MUJERES, PÍCAROS Y FUGAS: MEMORIAS DE LA GUERRA DE MaLVINAS

Verdad y Justicia, disputó y resignificó los sentidos de la guerra de Malvinas. Tal vez el movimiento más profundo que trajo aparejado el trigésimo aniversario del conflicto bélico en 2012, reflexiona Federico Lorenz (2013), fue ubicarlo dentro del proceso colectivo que investiga y responsabiliza socialmente la última dictadura cívico-militar; sabiendo que lo que está en juego hoy, más allá de las Islas del Atlántico Sur, es la forma de narrar la guerra. Piedras dentro de la Piedra, inspirada en aquella ficción inaugural sobre Malvinas, Los Pichiciegos de Fogwill, escrita al calor de los acontecimientos de 1982, se abre a sentidos polivalentes que disputan, hoy, la guerra como gesta. La obra de Mazover "desordena la representación sobre Malvinas" para usar las palabras de su autora; y se inscribe en esos relatos que desacomodan la teleología de patria y guerra, fundante de la argentinidad, según elabora Martín Kohan.

Piedras... se otorga esa libertad para carcomer nociones fundamentales que sostienen la guerra simbólicamente, que para Kohan solo le caben a la ficción literaria. Ni la política institucional ni el género testimonial pueden o quieren alejarse de la (justa y necesaria) denuncia sobre las atrocidades de la guerra (como las maniobras del gobierno militar para perpetuarse en el gobierno, o los crímenes de lesa humanidad cometidos contra soldados y conscriptos). Al género testimonial le cuesta abandonar versiones victimizantes que, en última instancia, nunca desafían la lógica primordial de la guerra, nunca cuestionan lo nacional. La dramaturgia de Mazover se contagia de esa libertad que tiene (parte de) la ficción literaria para sacudir los pilares de la identidad nacional; parodiar la patria; burlarse del honor; ridiculizar el sacrificio. Sus personajes no son ni víctimas ni héroes: 
son desertores que se resisten y se sustraen, no solo de la guerra, sino de toda pertenencia a la nación. Interrogan la complicidad civil. Desnudan los negocios de la guerra o la guerra como negocio. Crean lo común-pero desacoplado de la "comunidad nacional". Construyen un espacio para sobrevivir-o para vivir en común-material y afectivamente, tejiendo vínculos no reglados por el Estado Nación. Y además, Piedras..., también en sintonía con su tiempo memorial, recupera la participación de las mujeres en la guerra. Pero a diferencia de otras producciones teatrales contemporáneas, las mujeres de Piedras... no son fantasías proyectadas por soldados; ni objetos victimizados por el abuso sexual de superiores militares; ni por la división sexual del trabajo al servicio de la maquinaria bélica. Tampoco son madres sufrientes de hijos combatientes. Las de Piedras... son mujeres empoderadas que se burlan, resisten, se abstraen del conflicto bélico y de la nación. Son co-creadoras, junto a sus compañeros varones, del espacio común donde refugiarse y disociarse, al menos por un tiempo, del absurdo de la guerra.

\section{REFERENCIAS BIBLIOGRÁFICAS}

Aramburú, Roxana. "Mares de Piedra”, manuscrito, 2015.

Banfi, Lola. "Grietas", manuscrito, 2015.

Carbajal, Mariana. "Las Mujeres que fueron parte de la guerra”, Página 12, 2 de abril de 2015, http://www.pagina12.com.ar/diario/elpais/1-269555-2015-04-02. html

Elizabeth Jelin, "Víctimas, familiares o ciudadano/as? Las luchas por la legitimidad de la palabra”. En Crenzel, Emilio (comp.). Los desaparecidos en la Argentina. 
DE MUJERES, PÍCAROS Y FUGAS: MEMORIAS DE LA GUERRA DE MaLVINAS

Memorias, representaciones e ideas (1983-2008). Buenos Aires: Editorial Biblos, 2010, pp. 227-250.

Gamberro, Carlos. Las Islas. Buenos Aires, Edhasa, 2012.

Fernández, Cristina, Discurso Inaugural del Faro de la Soberanía, 10 de junio, 2015. Disponible en https://www.youtube.com/watch?v=fYDGpR-2RAU

Fogwill, Rodolfo Los Pichiciegos. Buenos Aires: Interzona, 2012, [1983].

Kohan, Martín "A salvo de Malvinas". Bazar Americano. septiembre-octubre 2014, AÑO XI, No 48. 2014 a. . El pais de la Guerra. Buenos Aires: Eterna Cadencia. 2014b

Lorenz, Federico Guillermo. "Testigos de la derrota Malvinas: los soldados y la guerra durante la transición democrática argentina, 1982-1987”. En Perotin-Dumon, Anne (comp.) Historizar el pasado vivo en América latina, Buenos Aires, Edhasa, 2007, pp. 3-63.

. Unas Islas demasiado famosas. Malvinas, Historia, Politica. Buenos Aires: Capital Intelectual, 2013.

Mazover, Mariana Piedras dentro de la Piedra. Buenos Aires: Libretto, 2014.

Panero, Alicia. Mujeres Invisibles. 2014.

Parrilla, Juan Pablo. "La silenciada historia de las veteranas de Malvinas", Infobae, 31 de marzo, 2015. http://www.infobae.com/2015/03/31/1719360-la-silenciada-historia-las-veteranas-malvinas,

Perera, Verónica. "Activismo cultural y derechos humanos hoy: Nuestro Teatro 2014” en Letra. Imagen. Sonido L.I.S. Ciudad Mediatizada. Año VII. \# 14, Segundo Semestre 2015, Buenos Aires, pp. 201-218.

Rodríguez, Fermín. "Los Pichyciegos, de Rodolfo Fogwill. Una economía de guerra”. Ponencia presentada en el XXXIV International Congress of the Latin American Studies Association, Decir la guerra en América Latina, Nueva York, 27-30 de Mayo 2016. 
Taylor, Diana.. "Military Males, "Bad Women" and a Dirty, Dirty War" in Disappearing Acts. Spectacles of Gender and Nationalism in Argentina's Dirty War. Duke Unversity Press. 1997 